PATIENT SAFETY

H.M. Hussein

A.L. Georgiadis

A.I. Qureshi

\section{Point-of-Care Testing for Anticoagulation Monitoring in Neuroendovascular Procedures}

\begin{abstract}
SUMMARY: POC testing is defined as diagnostic testing at or near the site of patient care. Rapid measurement of the intensity of anticoagulation and, more recently, platelet inhibition allows dose titration of adjuvant medications such a heparin and antiplatelet agents during neuroendovascular procedures. However, knowledge among practicing physicians regarding the pathophysiologic basis of these measurements and variations in knowledge about the differences among devices is often limited. This review discusses the role of anticoagulation in endovascular procedures and the currently available $\mathrm{POC}$ tests for anticoagulation monitoring.
\end{abstract}

ABBREVIATIONS: $\mathrm{ACT}=$ activated clotting time; Anti-Xa = quantitative chromogenic heparin assay aPTT = activated partial thromboplastin time; $\mathrm{AT}=$ antithrombin; $\mathrm{Cl}=$ confidence interval; $\mathrm{GP}$ $\mathrm{Ilb} / \mathrm{ll} \mathrm{la}=$ glycoprotein $\mathrm{Ilb} / \mathrm{llla}$; Hemonox-CT = Hemonox clotting time; HIT = heparin-induced thrombocytopenia; HMT = Heparin Management Test; IV = intravenous; LMWH = low-molecularweight heparin; $\mathrm{MI}=$ myocardial infarction; $\mathrm{OR}=$ odds ratio; $\mathrm{PCl}$ = percutaneous coronary intervention; $\mathrm{POC}=$ point of care; UFH $=$ unfractionated heparin
$T^{1}$ hromboembolism ensues from activation of platelets and the coagulation cascade and is a major source of complications during endovascular procedures. Multiple studies have demonstrated accelerated platelet activation during coronary and cerebral angioplasty. ${ }^{1,2}$ The coagulation cascade (Fig 1) consists of a sequential conversion of a series of proenzymes, or inactive precursor proteins (zymogens) to active enzymes, resulting in the formation of thrombus. It can be divided into 3 pathways: the extrinsic pathway (tissue factor and factor VIIa), which is the primary activator of the cascade; the intrinsic pathway (factors XIIa, XIa, IXa, and VIIIa), which amplifies the cascade; and the common pathway (factor Xa, factor $\mathrm{Va}$, and thrombin), which generates thrombin and fibrin.

Vessel injury and the introduction of foreign bodies set off the coagulation cascade. ${ }^{3}$ Catheters and wires used in endovascular procedures are thrombogenic, independent of intimal injury. ${ }^{3}$ Traversing atherosclerotic lesions with guidewires and catheters can dislodge plaque or thrombus. Inflation of balloons can produce intimal cracks, flaps, or dissections, all of which act as thrombogenic surfaces. ${ }^{3}$ In vivo studies have demonstrated that platelets rapidly accumulate on the stent surface after placement, especially if the underlying artery is injured. ${ }^{4}$ The role of fibrin and platelets in stent-related thrombosis has been confirmed in pathologic studies. ${ }^{5}$

Anticoagulants and antiplatelet agents are, therefore, essential for reducing the rate of thromboembolic complications. On the other hand, their use may increase the risk of bleeding complications. In this review, we will focus on anticoagulants and available POC devices that measure anticoagulation.

From Zeenat Qureshi Stroke Research Center, University of Minnesota, Minneapolis, Minnesota.

Please address correspondence to Haitham M. Hussein MD, Department of Neurology, Zeenat Qureshi Stroke Research Center, University of Minnesota, 420 Delaware St. SE, MMC 295, Minneapolis, MN 55455; e-mail: husseihm@gmail.com

Indicates open access to non-subscribers at www.ajnr.org

http://dx.doi.org/10.3174/ajnr.A2621

\section{Brief Overview of Anticoagulant Medications}

Anticoagulants reduce the activity of proteases in the coagulation cascade. On the basis of their mechanism of action (Fig 1), anticoagulants can be divided into 4 major groups: vitamin $\mathrm{K}$ antagonists (warfarin), heparins (UFH and LMWH), direct thrombin inhibitors, and direct factor Xa inhibitors. This review will focus on the anticoagulants relevant to endovascular procedures: UFH, LMWH, and parenteral direct thrombin inhibitors.

\section{UFH}

UFH activates AT, which neutralizes multiple enzymes, especially factors IIa (thrombin) and Xa. Individual patients respond differently to the same dose of heparin, largely due to differences in their levels of acute-phase-reactant proteins, which can bind and neutralize heparin. Other factors that can interfere with heparin efficacy include AT deficiency, increased heparin clearance, and elevation in factor VIII and/or fibrinogen. ${ }^{6}$ Monitoring of the anticoagulant effects of UFH by means of the aPTT or ACT is, therefore, essential. ${ }^{7}$

\section{LMWH}

LMWHs are produced by depolymerization of heparin. ${ }^{6}$ LMWHs exert their anticoagulant properties by activating AT. However, they have a much smaller effect on factor IIa and are thus relatively factor $\mathrm{Xa}-$ specific. ${ }^{7}$ LMWHs cause less platelet activation and exhibit less binding to cells and plasma proteins compared with UFH. ${ }^{8}$ Therefore, LMWHs have more predictable pharmacokinetic and pharmacodynamic properties and a lower risk of side effects. ${ }^{6}$ Recently, the safety and efficacy of IV LMWH anticoagulation for patients undergoing PCI has been demonstrated. ${ }^{9}$ LMWH activity can be measured by chromogenic anti-Xa. More recently, POC tests such as Hemonox clotting time (measured by the Hemochron Jr. Hemonox device; International Technidyne, Edison, New Jersey) ${ }^{10}$ and the Enox test (measured by the Cascade device; Helena Laboratories, Beaumont, Texas $)^{11}$ have been developed to monitor the anticoagulant effect of LMWH. Currently available LMWHs 


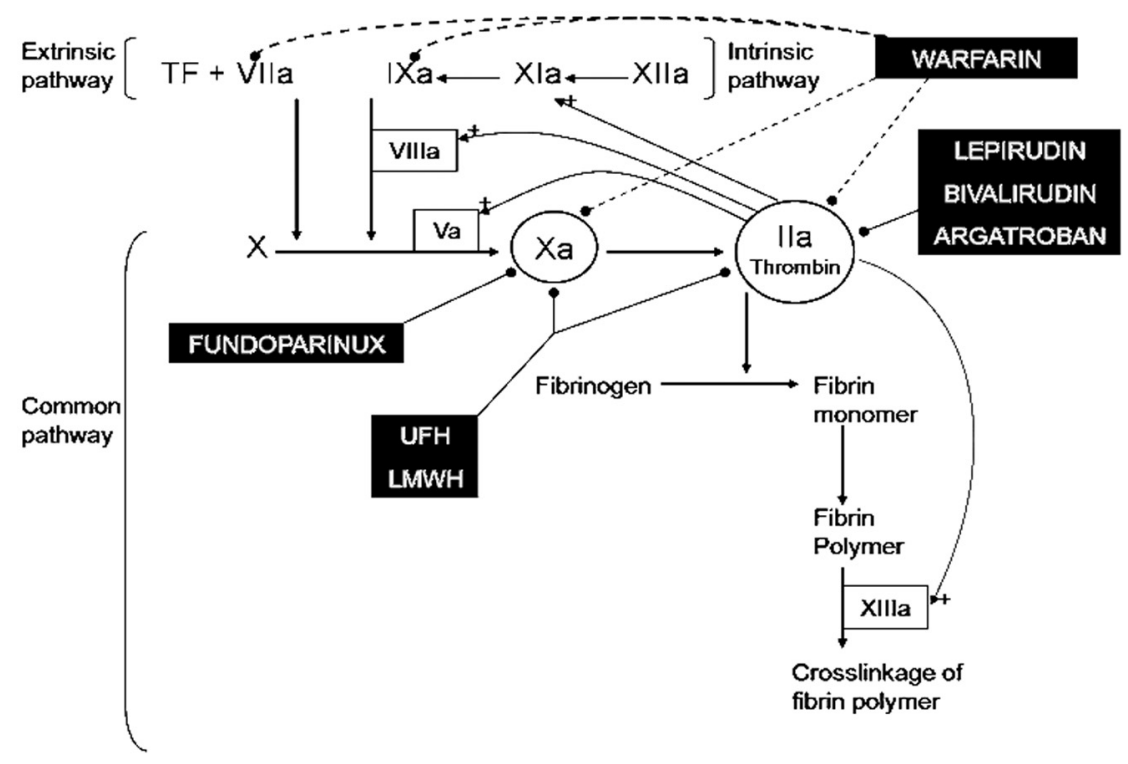

Fig 1. Simplified diagram depicting the coagulation cascade and targets of action of different anticoagulants. The coagulation cascade consists of the intrinsic, extrinsic, and common pathways. Note the positive feedback effect of thrombin on further activation of the intrinsic and common pathways. All anticoagulants target factors of the intrinsic and common pathway except warfarin, which decreases the rate of hepatic synthesis of factor VII.

in the United States include enoxaparin, tinzaparin, and dalteparin.

\section{Fondaparinux}

Fondaparinux is a synthetic pentasaccharide structurally related to the AT-binding site of heparin. It potentiates the antifactor Xa activity of AT. ${ }^{7}$ Fondaparinux is not currently used in endovascular procedures because it may be associated with a slightly increased risk of coronary guide-catheter thrombus formation. $^{9}$

\section{Direct Thrombin Inhibitors}

Hirudin was the first direct thrombin inhibitor to be used clinically. It directly and irreversibly binds with thrombin. Lepirudin is a recombinant form of hirudin. ${ }^{12}$ Lepirudin has 2 important side effects: 1) the formation of antibodies against hirudin, which occurs in up to $40 \%$ of patients and can prolong the plasma half-life of lepirudin, resulting in drug accumulation; and 2) anaphylaxis, which can occur if patients with antibodies are re-exposed to the drug. In the United States, lepirudin is licensed for the treatment of thrombosis complicating HIT.

Bivalirudin is a synthetic hirudin analog with a half-life of 25 minutes. The binding of bivalirudin to the active site of thrombin is transient. ${ }^{13,14}$ Several trials have suggested its superiority over UFH (alone or in combination with GP IIb/IIIa inhibitors) during PCI in reducing the risk of bleeding complications. ${ }^{13,15-19}$ Bivalirudin is licensed as an alternative to heparin in patients with HIT who require PCI. ${ }^{6}$

Argatroban is a competitive thrombin inhibitor. Its plasma half-life is 45 minutes. ${ }^{20}$ Argatroban is licensed for treatment and prevention of HIT-associated thrombosis and for anticoagulation during PCI when heparin is contraindicated because of a recent history of HIT. ${ }^{6}$ Activity can be monitored by ACT or aPTT. ${ }^{21}$

\section{Methods of Measurement of Anticoagulation Intensity}

\section{Anti-Xa assay}

The anti-Xa measures heparin concentration indirectly by using either the thrombin or factor Xa enzyme as the assay reagents. For LMWHs, factor Xa assay is used. ${ }^{22,23}$ No POC test is available.

\section{aPTT}

The aPTT test is used to monitor anticoagulation with heparin. It measures the time in seconds from the activation of factor XII to the formation of fibrin clot, thus assessing the integrity of the intrinsic and common pathways of coagulation. However, at heparin concentrations of $>1 \mathrm{U} / \mathrm{mL}$, aPTT is infinitely prolonged, and it can, therefore, not be used to monitor anticoagulation during cardiac surgery or endovascular procedures.

\section{$A C T$}

The ACT is a whole-blood clotting time test (Table 1$).{ }^{24}$ It is routinely used to monitor anticoagulation during cardiopulmonary bypass surgery and endovascular procedures. Clotting is initiated in a blood sample by an activator of the intrinsic pathway (most commonly Celite [Celite Corporation, Santa Barbara, California], glass particles, or kaolin), and the time until clot formation is measured in seconds. ${ }^{25}$ ACT values are device-specific. All available devices have acceptable reproducibility, but reference and therapeutic ACT ranges vary considerably. ${ }^{21,26,27}$ Therefore, every ACT test should be regarded as unique.

ACT is determined predominantly by the anti-IIa activity of the anticoagulant. Thus, ACT is higher with heparin or bivalirudin than with LMWH for the same intensity of anticoagulation. ${ }^{28}$ However, ACT can be used to monitor LMWH anticoagulation with appropriate adjustments. ${ }^{29,30}$

In a study comparing aPTT with ACT, a total of 175 paired 


\section{Table 1: Overview of some important facts on anticoagulation and ACT}

ACT and Anticoagulation Facts

Celite, kaolin, and glass are activators used to measure ACT that yield different results

Celite-ACT is significantly longer than kaolin ACT

ACT values from a particular device are reproducible and correlate with antiXa values

ACT is device-specific even if the activator used is the same

ACT following administration of heparin varies based on heparin-dependent (heparin responsiveness/resistance) and heparin-independent (hemodilution, hypothermia, platelet count, race, and so forth) factors

LMWH anticoagulation can be monitored by ACT

Hemonox-CT is a more specific POC test for LMWH

Concomitant use of abciximab increases ACT; eptifibatide leads to less marked changes in ACT

Concomitant aprotinin administration affects Celite-ACT more than kaolinACT

Heparin concentrations are divided into high ( $>1 \mathrm{U} / \mathrm{mL})$ and low $(<1 \mathrm{U} / \mathrm{mL})$ Kaolin-based ACT is less accurate in low-intensity anticoagulation

Glass beads in a plastic tube are more effective in moderate heparin concentrations

Hemochron produces lower ACT values than the Automated Coagulation Timer System (previously HemoTec)

The corresponding anti-Xa values are needed to establish a therapeutic ACT range for a particular device

Institutions should establish their individual therapeutic ACT ranges

ACT and aPTT measurements were obtained by using the HemoTech device (Medtronic, Minneapolis, Minnesota) in a random subset of patients undergoing PCI procedures at baseline, after heparinization, and at 4- to 6-hour intervals after the procedure. The aPTT was limited by absolute upper and lower limits of 150 and 22 seconds, respectively, while there were no such limits for ACT values. After exclusion of limiting values there was a strong correlation between ACT and aPTT $(r=$ $0.92, P<.001) .^{31}$ In another study, 30 patients undergoing PCI were treated with heparin and 30 were treated with heparin plus abciximab (c7E3). Heparin levels, POC ACT, and laboratory and POC aPTT were calculated. Neither aPTT test could be used to measure anticoagulation due to lack of clot formation, whereas ACT was measurable albeit affected by abciximab. ${ }^{32}$

ACT levels following UFH administration can vary substantially on the basis of heparin-dependent (individual patient response) and heparin-independent factors. Heparin-independent factors include hemodilution, concentration of clotting factors, hypofibrinogenemia and other coagulopathies, hypothermia, and platelet count. ${ }^{26,33}$ Recent data suggest that there may be a difference in heparin sensitivity among races. ${ }^{34}$

ACT is also affected by concomitant administration of other antithrombotic agents. For example, when eptifibatide is added to heparin, the corresponding anti-Xa level for the same Hemochron ACT (International Technidyne) is lower. ${ }^{21}$ Abciximab has a similar effect on ACT but of higher magnitude. ${ }^{21,25}$ Another example is aprotinin, which affects Celitebased ACT but not kaolin-based ACT. ${ }^{26}$

Venous ACT was found to be slightly but significantly greater than arterial ACT in 1 prospective study that sampled arterial and venous blood in 48 patients undergoing PCI. ${ }^{35}$ This difference, however, did not affect the complication rate or the amount of heparin used during the procedure.
There is no criterion standard with which ACT can be compared, which makes validation very difficult. Most new ACT tests/devices are compared with already existing ones. Because of this variability, the American College of Chest Physicians Seventh Conference on Antithrombotic and Thrombolytic Therapy recommended establishing a heparin concentration-derived therapeutic range for UFH at individual institutions. ${ }^{36,37}$ There are no data on how rigorously this recommendation is being followed.

\section{Therapeutic Anticoagulation Range: Data Derived from PCI Studies}

The lower threshold is determined to prevent occurrence of ischemic events. ACT of 250 seconds by HemoTech has been suggested as the lower anticoagulation threshold for PCI. ${ }^{38} \mathrm{In}$ a comparison among 103 patients who had major complications (group I) and 400 patients without complications (group II), group I had significantly lower ACT after heparin therapy and at the end of the procedure. Complications occurred in all patients with a final ACT of $<250$ seconds but in only $0.3 \%$ of patients with a final ACT of $>300$ seconds. ${ }^{38}$ In another retrospective review, ${ }^{39} 62$ patients with abrupt vessel closure were identified among 1290 consecutive patients who underwent nonemergent PCI. This group was compared with a matched control population of 124 patients who did not experience abrupt vessel closure. Patients who exhibited abrupt closure had a significantly lower initial ACT as measured by the Hemochron device with a median ACT of 350 seconds (interquartile range, 309-401 seconds) versus 380 seconds (interquartile range, 335-423 seconds, $P=.004$ ). The minimum ACT was also lower for the abrupt closure group, with a median value of 345 seconds (interquartile range, 287-387) versus 370 seconds (interquartile range, 321 to 417 seconds, $P=.014)$. Higher ACTs were not associated with an increased likelihood of major bleeding complications. ${ }^{39}$

The Treat Angina with Aggrastat and Determine Cost of Therapy with an Invasive or Conservative Strategy-Thrombolysis In Myocardial Infarction 18 study randomized 2220 patients to either early invasive (angiography within 4-48 hours and, if indicated, tirofiban and heparin) or early conservative arms of management. ${ }^{40}$ The average peak ACT was $249 \pm 53$ seconds among those who had the composite end point of death or MI by 7 days $(n=19)$ compared with $286 \pm$ 88 seconds in patients who did not have adverse events $(n=$ $359, P=.022$ ). Likewise, at 30 days, the peak ACT was higher in patients who had a composite event $(248 \pm 51$ seconds, $n=$ 22) compared with those without an adverse event ( $287 \pm 88$ seconds, $n=356 ; P=.012$ ). Kaplan-Meier survival analysis demonstrated a higher event rate at 30 days in patients with an ACT $\leq 250$ seconds (Cox hazard ratio, 2.33; $P=.05$ ). There was no increase in major or minor bleeding events associated with an ACT of $>250$ seconds or bleeding events from index hospitalization through 24 hours after discontinuing the administration of tirofiban. This study had, however, several limitations.

The upper ACT threshold for PCI has not been clearly established. In a subanalysis from the Safety and Efficacy of Enoxaparin in PCI Patients, an International Randomized Evaluation trial, which randomized patients to enoxaparin $(n=2298)$ or UFH $(n=1230)$, major bleeding increased 
significantly with Hemochron ACT of $>325$ seconds (OR, 1.6; 95\% CI, $1.1-2.2$ per 100 seconds; $P=.04) .{ }^{41}$ There was a significant relationship between ischemic events and ACT of $<325$ seconds (OR, 0.7; 95\% CI, 0.2-0.8 per 100 seconds; $P=$ $.006)$. In a meta-analysis of 6 randomized controlled PCI trials, Chew et $\mathrm{al}^{42}$ studied the maximal ACT values from the placebo arms (3485 subjects). Maximal ACT correlated with the incidence of major and minor bleeding. The lowest level of bleeding $(8.6 \%)$ was observed in the range of 325-350 seconds, and it increased to $12.4 \%$ at $350-375$ seconds. A substantial increase in bleeding events was observed when ACT values exceeded 400 seconds. ${ }^{42}$

Other studies failed to show any correlation between bleeding complications and ACT values. Brener et $\mathrm{al}^{43}$ retrospectively studied 2280 consecutive patients with ST-segment elevation MI treated with PCI and attempted to correlate bleeding complications with intraprocedural peak ACT values categorized into quartiles. The incidence of bleeding complications was $6.6 \%, 5.9 \%, 6.9 \%$, and $7.3 \%$, respectively $(P=$ $.81) .{ }^{43}$ In an ad hoc analysis of the Early Discharge after Transradial Stent placement of Coronary Arteries trial, the effect of ACT (Hemochron device) at the end of the procedure on postprocedure complications including bleeding was studied. ${ }^{43}$ The study included 1234 consecutive patients with acute coronary syndrome treated with PCI. ACT values were divided into tertiles. The median final ACT was 312 seconds (interquartile range, 279-344). At 30 days, the incidence of major bleeding was not different in the higher tertile than in the other 2 tertiles $(0.7 \%, 1 \%$, and $2 \%$, respectively; $P=.20)$. The transfusion rate was significantly higher in the lowest tertile $(2.2 \%$ versus $0.5 \%$ and $0.7 \%, P=.042) .{ }^{44}$

\section{Optimal ACT for Neuroendovascular Procedures}

In current neuroendovascular practice, anticoagulation is usually achieved by an IV bolus at the beginning of the procedure with or without subsequent infusion. ${ }^{45}$ Dosing is, however, not standardized. Fixed doses of $3000 \mathrm{U},{ }^{46} 5000 \mathrm{U},{ }^{47}$ and $10,000 \mathrm{U},{ }^{48}$ as well as weight-based dosing ranging from 50 $\mathrm{U} / \mathrm{kg}^{49}$ to $100 \mathrm{U} / \mathrm{kg}^{50}$ have been used. Reported target ACT ranges have varied from $150-200$ seconds to $350-400 \mathrm{sec}-$ onds. ${ }^{50-53}$ Data regarding the optimal ACT for neuroendovascular procedures are scant because testing methods and ACT goal ranges are not commonly reported. Most of the evidence available is based on experts' opinion and/or extrapolated from PCI literature. Such evidence does not take into account important anatomic differences between cerebral and coronary arteries, which make the neuroendovascular procedures longer, more difficult technically, and associated with a higher risk of dissection, thromboembolism, and vessel rupture with fatal subarachnoid hemorrhage.

In one retrospective series, data from 605 consecutive patients who underwent carotid artery stent placement with adjunct intraprocedural UFH were reviewed. ACTs were measured with Hemochron devices. ${ }^{54}$ A peak procedural ACT of 250-299 seconds $(n=277)$ was associated with significantly lower combined event rates (stroke, MI, or death) at 7 days (2.2\% versus $6.6 \%$; relative risk reduction, $66.7 \% ; P=.014$ ) and 30 days $(2.9 \%$ versus $10.4 \%$; relative risk reduction, $72.1 \% ; P<.001)$ compared with an ACT of 300-350 seconds $(n=212)$. There was also a nonsignificant reduction in the rate of major bleeding events with a peak procedural ACT of $250-299$ seconds compared with 300-350 seconds (3.2\% versus $6.1 \%, P=.127) .{ }^{54}$

Castellan et $\mathrm{al}^{50}$ studied 29 symptomatic extracranial stenotic lesions treated with stent placement with a distal protection device. Patients were given a heparin bolus of $100 \mathrm{IU} / \mathrm{kg}$ during the procedure. ACT was measured by Hemochron 401 (Celite) just before stent placement. The mean ACT was $406 \pm$ 56 seconds (range, $320-550$ seconds). In 9 procedures, the filter was completely occluded with debris (mean ACT, $367 \pm$ 42 seconds); and in 20 procedures, the filter remained patent (mean ACT, $423 \pm 54$ seconds; $P=.0009$ ). ACTs below 380 seconds were associated with system occlusion (defined as completely occluded filter with minimal passage of contrast between filter and arterial walls) in $66 \%$. Only 1 patient exhibited minor stroke symptoms that resolved following protection device withdrawal and restoration of flow. The authors suggested an ACT of 400 seconds as the goal for endovascular procedures performed with a filter device. ${ }^{50}$ However, 2 major randomized trials that showed noninferiority of carotid artery stent placement compared with endarterectomy, the Stent placement and Angioplasty with Protection in Patients at High Risk for Endarterectomy ${ }^{55}$ trial and the Carotid Revascularization Endarterectomy versus Stent placement Trial, ${ }^{56}$ used a 250- to 300-second ACT range for carotid stent placement.

One common practice is to use different ACT ranges, depending on the procedure-specific likelihood of thromboembolic complications. For low-risk procedures such as embolization of aneurysms and arteriovenous malformations, ACT can be maintained at 250-300 seconds, whereas in high-risk procedures such as angioplasty and stent placement, a higher ACT range of 300-350 seconds is recommended. ${ }^{3}$

\section{$A C T$ and $L M W H$}

Despite the clinical and biochemical benefits of LMWH over $\mathrm{UFH}$, the presumed lack of POC monitoring has limited the use of LMWH in catheterization laboratories. However, when LMWH agents are administered intravenously, the plasma levels are high enough to render POC monitoring possible. In 1 study, the effect of UFH and 2 LMWH agents (enoxaparin and dalteparin) on Hemochron ACT, aPTT, and anti-Xa assay was compared in 130 patients undergoing PCI. ${ }^{57}$ All 3 agents induced significant elevation in aPTT and ACT. The anticoagulant effect of LMWH was significant 5 minutes following administration and remained so for 2 hours. The magnitude of the ACT dose-response was approximately one-half the magnitude of that obtained by UFH. There was no difference in the rate of hemorrhagic complications between groups. ${ }^{57}$

Hemonox-CT (International Technidyne) is a new assay that was specifically developed to monitor LMWH anticoagulation. It measures ACT as well as the anti-Xa activity of LMWH. In a study of 90 patients undergoing PCI with administration of UFH, enoxaparin, or dalteparin, Hemonox-CT, ACT, and anti-Xa assays were monitored. Minutes after IV administration of enoxaparin and dalteparin, the mean Hemonox-CT increased to 171 and 214 seconds, respectively (from a baseline of 68 seconds for both groups). ${ }^{58} \mathrm{UFH}$ induced a higher Hemonox-CT response (800 seconds). At all time points, Hemonox-CT was higher than the ACT. Peak Hemonox-CT was associated with therapeutic anti-Xa activ- 
ity. The enoxaparin- and dalteparin-treated patients successfully underwent PCI without major hemorrhagic complications. ${ }^{58}$ These results have been replicated. ${ }^{10}$ Another study used Hemonox-CT to identify patients with an insufficient anti-Xa activity level $(<0.5 \mathrm{U} / \mathrm{mL})$ among 296 patients undergoing PCI. ${ }^{59}$ Hemonox-CT, aPTT, and chromogenic anti-Xa activity levels were measured at baseline and 10 minutes after IV administration of enoxaparin. A Hemonox-CT threshold value of 120 seconds was associated with 94\% sensitivity, $73 \%$ specificity, $74 \%$ positive predictive value, and $95 \%$ negative predictive value.

\section{ACT and GP IIb/IIIa Inhibitors}

Evidence from basic and clinical investigations suggests that abciximab may have greater anticoagulant effect compared with small-molecule inhibitors (eptifibatide and tirofiban). ${ }^{60}$ The effect of abciximab (c7E3) on ACT was observed in early clinical trials. In the Evaluation of c7E3 for the Prevention of Ischemic Complications trial, 2099 patients undergoing PCI with a high risk of abrupt vessel closure were randomized to receive placebo $(n=696)$ or abciximab $(n=1403) .{ }^{61}$ Those receiving abciximab had a higher mean ACT despite receiving less procedural heparin (401 versus 367 seconds, $P<.001$ ). Abciximab caused an increase in ACT of approximately 35 seconds. ${ }^{61}$ In an in vitro study, the ACT values of the heparinized but not native samples were significantly prolonged by the addition of GP IIb/IIIa inhibitors. The effect of abciximab on blood anticoagulated with UFH could be equated with the addition of $0.4-0.5 \mathrm{U} / \mathrm{mL} \mathrm{UFH}^{6}{ }^{62}$ In a more recent in vivo study, this effect was even higher. ${ }^{32}$ The median ACT-prolonging effect of abciximab was equivalent to that of 0.68 $\mathrm{U} / \mathrm{mL}$ heparin.

In a study of 125 patients undergoing PCI, ACT increased following heparin but not eptifibatide boluses. ${ }^{63}$ Tirofiban is believed to have a similar effect on ACT on the basis of in vitro data, ${ }^{64}$ and this is reflected in the guidelines. ${ }^{65}$

No association between low ACT and ischemic complications was demonstrated in prospective trials among patients receiving GP IIb/IIIa inhibitors. Data from the Do Tirofiban and ReoPro Give Similar Efficacy Outcome Trial comparing abciximab with tirofiban did not show statistically significant differences in ACT values achieved or in clinical outcome (ischemic or bleeding complications) ${ }^{60}$ In the Enhanced Suppression of the Platelet IIb/IIIa Receptor with Integrilin Therapy trial, 2064 patients undergoing coronary stent placement under heparin anticoagulation with target ACTs of 200-300 seconds were randomized into 2 arms - placebo versus eptifibatide infusion, which was started immediately before the procedure. ${ }^{66}$ The sample was trichotomized on the basis of ACT into 3 groups (ACT of $<244$ seconds; 245-292 seconds, and $>292$ seconds). There was no association between decreasing ACT levels and the rate of ischemic events in the treatment or placebo arms. Major bleeding rates increased with higher ACTs in the eptifibatide-treated patients. ${ }^{66}$

\section{Commonly Used POC Anticoagulation Measurement Devices}

The first POC device (Hemochron) was designed in 1972 to measure ACT during cardiopulmonary bypass surgery. Commer- cially available devices are based on either cuvette or cartilage technology. They use different activators, aim for different end points, and have different end point-detection methods (Table 2). POC devices have become more user-friendly and automated, thus reducing operator-dependent variability.

\section{Hemochron Model Response}

Hemochron models, 8000, 801, and 401, FTCA51/ HRFTCA510, FTK-ACT/HRFTK-ACT, and P214 (International Technidyne) measure ACT in different modes specific to settings: high heparin concentration up to $6 \mathrm{U} / \mathrm{mL}$ (as used in cardiopulmonary bypass surgery), moderate heparin concentration (as used in hemodialysis and extracorporeal membrane oxygenation), and in the presence of aprotinin. Three different types of reagents are used on the basis of the specific mode: Celite in a glass tube for high heparin concentrations, glass beads in a plastic tube for moderate heparin concentrations, and kaolin in a glass tube if aprotinin is present. In these devices, a precision-aligned magnet is located within the test tube and the test well contains a magnetic detector. Following insertion of a whole blood sample into the well, the detector senses the magnet within the test tube as the tube slowly rotates. When clot begins to form, the magnet lifts within the tube and can no longer be sensed by the magnetic detector. The instrument gives an audible beep and displays the coagulation time. Normal values are provided by the manufacturer, but institutions are strongly encouraged to develop their own reference and target values. ${ }^{67}$ With this system, some studies have found that ACT can be used to monitor the LMWH anticoagulation effect. ${ }^{29,30}$

\section{Hemochron Jr. Signature +}

The Hemochron Jr. Signature + device, and its test, Hemochron Jr. ACT+ (International Technidyne), can measure ACT in high-intensity anticoagulation (heparin concentrations of $1.0-6.0 \mathrm{U} / \mathrm{mL}$ ). The blood is automatically mixed with kaolin reagent. The device then introduces $0.015 \mathrm{~mL}$ of this mixture into the test channel and disposes of the remaining blood. While the sample is moved back and forth, the speed of this motion is continuously assessed. As thrombus formation begins, sample velocity decreases. The elapsed time until a predetermined velocity is reached is automatically converted to a reference Celite-ACT value. The conversion is based on a study conducted by the manufacturer by using blood specimens from surgical $(n=79)$ and nonsurgical ( $n=$ 53) cardiac patients who were simultaneously assessed by using the Hemochron Jr. ACT + and the reference Celite-ACT. The results demonstrated a high degree of correlation $(r=$ 0.93 ) between the 2 tests. However, differences of $>100 \mathrm{sec}-$ onds have been observed as the clotting time increases. The linear regression describing the relationship of the 2 tests has been programmed into the device. The kaolin-based ACT+ clotting time may yield target ranges approximately $10 \%-15 \%$ shorter than corresponding Celite-ACT values. ${ }^{68}$ Normal values provided by the manufacturer range from 81 to $125 \mathrm{sec}$ onds for healthy donors and 96-152 seconds for hospitalized patients not receiving heparin. The manufacturer's recommendation for target ACT for PCI is 260-270 ACT+ seconds, 


\begin{tabular}{|c|c|c|c|c|c|}
\hline Manufacturer & Device & ACT Test & Reagent & Detection Method & Remarks \\
\hline \multirow[t]{4}{*}{$\begin{array}{l}\text { International } \\
\text { Technidyne }\end{array}$} & $\begin{array}{l}\text { Hemochron Jr. Signature, } \\
\text { Signature +, and } \\
\text { Signature Elite }\end{array}$ & ACT and ACT-LR & Kaolin & Optical & $\begin{array}{l}\text { Result is automatically } \\
\text { converted to a } \\
\text { reference Celite- } \\
\text { ACT value }\end{array}$ \\
\hline & Hemochron & 3 different ACT tests: & Celite in glass tube (high heparin & Mechanical & Other capabilities: \\
\hline & Response & $\begin{array}{l}\text { FTCA510, KACT, } \\
\text { P214 }\end{array}$ & $\begin{array}{l}\text { levels), kaolin in glass tube } \\
\text { (if aprotinin is present), } \\
\text { glass beads in plastic tube } \\
\text { (low heparin levels) }\end{array}$ & & $\begin{array}{l}\text { RxDx heparin/ } \\
\text { protamine dosing } \\
\text { system }\end{array}$ \\
\hline & $\begin{array}{l}\text { Hemochron Jr. } \\
\text { Hemonox }\end{array}$ & Hemonox-CT & $\begin{array}{l}\text { Proprietary lipidated } \\
\text { recombinant-rabbit-brain } \\
\text { tissue factor }\end{array}$ & Mechanical & $\begin{array}{l}\text { Designed specifically } \\
\text { to monitor LMWH }\end{array}$ \\
\hline \multirow[t]{2}{*}{ Medtronic } & HMS PLUS & ACT-HR & Celite & Mechanical & $\begin{array}{l}\text { Other capabilities: } \\
\text { heparin dose } \\
\text { response and } \\
\text { heparin protamine } \\
\text { titration }\end{array}$ \\
\hline & ACT PLUS & ACT-LR & Celite & Mechanical & \\
\hline Sienco & Sonoclot & $\begin{array}{l}\text { Aprotinin-insensitive } \\
\text { ACT (SaiACT) }\end{array}$ & Celite + clay & Mechanical & \\
\hline Abbott Laboratories & i-STAT & Celite-ACT, kaolin-ACT & Celite kaolin & Electrochemical & \\
\hline $\begin{array}{l}\text { Instrumentation } \\
\text { Laboratory }\end{array}$ & GEM PCL & ACT, ACT-LR & $\begin{array}{l}\text { Kaolin (for ACT), Celite + silica } \\
\quad \text { (for ACT-LR) }\end{array}$ & Optical & \\
\hline \multirow[t]{2}{*}{ Helena Laboratories } & Cascade & Celite-ACT & Celite & Photomechanical & $\begin{array}{l}\text { Can also perform Enox } \\
\text { and LMWH tests }\end{array}$ \\
\hline & $\begin{array}{l}\text { Actalyke XL, } \\
\text { Actalyke Mini ॥ }\end{array}$ & $\begin{array}{l}\text { Celite-ACT, kaolin- } \\
\text { ACT, glass-ACT, } \\
\text { MAX-ACT }\end{array}$ & $\begin{array}{l}\text { Celite, kaolin, glass, or a cocktail } \\
\text { of Celite, kaolin and glass }\end{array}$ & $\begin{array}{l}\text { 2-Point, } \\
\text { electromechanical }\end{array}$ & $\begin{array}{l}\text { Linear correlation with } \\
\text { heparin level } \leq 10 \\
\mathrm{U} / \mathrm{mL} \text { for } \mathrm{XL} \text { model } \\
\text { and } 6 \mathrm{U} / \mathrm{mL} \text { for } \\
\text { Mini II model tubes } \\
\text { can be used in } \\
\text { Hemochron system }\end{array}$ \\
\hline
\end{tabular}

Note: $-\mathrm{LR}=$ low range; $\mathrm{HR}=$ high range.

which corresponds to Celite-ACT of 300 seconds. However, the package insert indicates that each institution must establish its normal and target ranges on the basis of the unique characteristics of the patient population treated. ${ }^{67}$

\section{RxDx Heparin/Protamine Dosing System}

Protamine sulfate neutralizes the anticoagulant effect of heparin. It is commonly used to reverse heparin anticoagulation at the end of cardiopulmonary bypass surgery. Accurate dosing of protamine is important. Protamine dosing is weight-based. This does not take into account the interindividual variability of response to heparin. The Hemochron RxDx heparin/protamine dosing system (International Technidyne) helps individualize heparin and protamine doses. The system consists of the heparin response test, the protamine response test, and the protamine dose assay. It measures a patient's heparin sensitivity and incorporates the patient's estimated blood volume into a formula that calculates the heparin dose required to achieve target ACT. It can also calculate the dose of protamine needed to bring the ACT back to normal. Some of the Hemochron devices have RxDx capabilities. This method has been shown to decrease the dose of protamine administered, though it is not clear if it has an impact on outcome. ${ }^{69-71}$

\section{Hemochron Jr. Hemonox System}

Specifically designed to monitor anticoagulation with LMWH, the Hemochron Jr. Hemonox System, which mea- sures Hemonox-CT, is superior to ACT for assessing the effect of LMWH. ${ }^{58}$ Measured simultaneously with anti-Xa activity, the correlation between the 2 tests is $>0.85$ when values obtained at baseline (absence of drug), peak response (10 minutes post bolus), and sheath removal (60 minutes postbolus) are compared. ${ }^{10,72}$

\section{ACT PLUS Automated Coagulation Timer System}

The second POC system to appear on the market was the HemoTec device (Medtronic, Minneapolis, Minnesota, previously HemoTec), ${ }^{73}$ based on cartridge technology and Celite reagent. ACT cartridges are available in a variety of sensitivities to monitor the therapeutic activity of heparin at high or low concentrations.

Comparative studies have shown that ACT values as measured by Hemochron are 30-50 seconds higher than those measured by HemoTec in comparable samples. ${ }^{65}$ In a recent study, Hemochron ACT and ACT PLUS (Medtronic) were compared with anti-Xa levels in 32 patients undergoing PCI or diagnostic catheterization under heparin or argatroban. In patients who received heparin, ACT obtained by Hemochron was consistently higher than ACT PLUS, and the difference increased with higher ACTs. The divergence increased even more with concomitant administration of eptifibatide. In the argatroban group, the opposite relation was found; ACT PLUS values were higher than Hemochron ACT. ${ }^{21}$ 


\section{HMS Plus Hemostasis Management System (Previously} Hepcon)

This HMS Plus Hemostasis Management System (Medtronic) measures ACT in high-intensity anticoagulation and can also directly assess heparin concentration in samples. ${ }^{73}$ As with other devices, some studies showed good agreement between whole blood heparin concentration and either $\mathrm{ACT}^{74}$ or plasma anti-Xa levels ${ }^{75}$ whereas, other studies showed no significant correlation. ${ }^{76}$

An important feature of the HMS device is an in vitro individualized heparin dose-response assay. It is the Medtronic equivalent of the Hemochron $\mathrm{RxDx}$ system, but it assesses heparin concentration instead of ACT. In this method, a 3-point dose-response curve is drawn on the basis of baseline, $1.5 \mathrm{U} / \mathrm{mL}$, and $2.5 \mathrm{U} / \mathrm{mL}$ concentrations of heparin. From this curve, the heparin dose required to achieve the desired ACT is extrapolated. $^{77}$

\section{The HMT}

The HMT is a more recent test (Thrombolytic Assessment System, PharmaNetics [formerly Cardiovascular Diagnostics Inc], Raleigh, North Carolina) that measures the degree of heparin anticoagulation. The HMT uses a Celite activator. Citrated whole blood is added to the test cartridge and is inserted into the thrombolytic assessment system analyzer. The sample moves by capillary action, mixing with reagent and paramagnetic iron oxide particles, simultaneously starting a pulsating magnetic field that causes the paramagnetic iron oxide particles to move. As the sample clots, the decrease in paramagnetic iron oxide particle movement is detected and the elapsed time is displayed. ${ }^{78}$

One study compared HMT with HemoTech ACT in a sample of 10 adults and 10 pediatric patients undergoing cardiopulmonary bypass. ${ }^{78}$ All adults had both therapeutic ACT and HMT levels. Although children had therapeutic ACT levels, their HMT levels were subtherapeutic. The children had significantly higher thrombin-antithrombin complexes and prothrombin fragments than adults, indicating ongoing thrombin production. The authors argued that because the HMT method measures the change in movement on a microscopic rather than macroscopic scale, it seems less dependent on fibrinogen levels than traditional ACT methods. ${ }^{78}$

HMT has been used in endovascular procedures. In 1 study that prospectively enrolled 100 patients undergoing PCI, HMT correlated well with Hemochron ACT values $(r=0.64$, $P<.001) .{ }^{79}$ In another study, HMT was compared with $\mathrm{He}-$ moTec ACT in 68 patients undergoing PCI. Despite a good correlation $(r=0.77, P<.0001)$, the mean HMT was 41 seconds longer than the mean ACT. There was increasing disagreement between the 2 methods as the intensity of the anticoagulation increased..$^{80}$

\section{Sonoclot Coagulation and Platelet Function Analyzer}

There are different Sonoclot ACT assays that can be measured by the Sonoclot Analyzer (Sienco, Arvada, Colorado). These assays have different indications and use different activators. For example, SonACT uses Celite and is intended for monitoring large doses of heparin in absence of aprotinin. kACT uses a kaolin activator and is indicated for large doses of heparin with or without aprotinin. The SaiACT (aprotinin-sensitive ACT) uses a combination of Celite, which provides contact activation, and clay, which neutralizes aprotinin. ${ }^{81,82}$ The SaiACT test was reported to be reliable and to lead to more consistent heparin management that is less affected by aprotinin during cardiopulmonary bypass surgery. ${ }^{82}$

\section{i-STAT Device}

The i-STAT device (Abbott Laboratories, Abbott Park, Illinois) measures the i-STAT Celite-ACT. The device is unique in that the end point is chemical (the conversion of a thrombin substrate other than fibrinogen), detected by using an electrochemical sensor. ${ }^{83}$ In 1 study, i-STAT ACT was compared with Hemochron Celite-ACT in 165 samples from 29 patients undergoing cardiopulmonary bypass or hemodialysis. Overall, there was a mean difference of $24 \pm 101$ seconds between the 2 methods-i-STAT ACT being lower. The difference increased with i-STAT ACT values by $>400$ seconds. The i-STAT ACT correlated well with anti-Xa levels $\left(r^{2}=0.79\right)$ in the cardiopulmonary bypass group; however, the correlation was less robust in the hemodialysis group $\left(r^{2}=0.55\right) .^{83}$

\section{GEM PCL PLUS Device}

The GEM PCL PLUS Device (Instrumentation Laboratory, Lexington, Massachusetts) can perform 2 tests: ACT (for heparin levels of 1-6 U/mL) and ACT-LR (for heparin levels of $0-2.5 \mathrm{U} / \mathrm{mL}$ ) by using optical detection with a kaolin reagent for ACT and Celite plus silica for ACT-LR. Considerable variance was observed in values obtained by using this instrument compared with values obtained from Hemochron and ACT II in 11 patients undergoing cardiopulmonary bypass surgery. ${ }^{84}$

\section{Actalyke Device}

Actalyke (Helena Laboratories, Beaumont, Texas) offers a full line of Actalyke ACT tubes, including traditional glass beads, kaolin, Celite, plus a newer ACT test-MAX-ACT (Helena Laboratories). MAX-ACT uses a cocktail of Celite, kaolin, and glass as an activator to ensure maximal activation of factor XII at the beginning of the reaction. The test aims to reduce the variability between individual responses to various activators, most likely due to the multispecies nature of factor XII. ${ }^{85} \mathrm{Un}$ der maximal factor XII activation, the prolongation of thrombus formation will depend less on the variability in intrinsic coagulation and more reliably on heparin activity. ${ }^{86}$ Actalyke uses a unique end point detection system: 2-point clot detection. This 2-point system enables the analyzer to detect a thrombus at early fibrin formation. ${ }^{85}$ In a study of 27 patients who underwent cardiopulmonary bypass surgery, MAX-ACT values were nonsignificantly shorter than Hemochron-ACT values immediately after heparin bolus. This difference was more prominent with hypothermia. ${ }^{86}$

\section{Viscoelastic POC}

Another category of POC devices monitors coagulation on the basis of assessing the viscoelastic properties of whole blood. Three commonly used systems are the TEG (Haemoscope Corporation, Niles, Illinois), the ROTEM (Pentapharm, Mu- 
nich, Germany), and the Sonoclot Analyzer (Sienco). Both the TEG and ROTEM measure and graphically display the changes in viscoelasticity of all stages of the developing and resolving clot. The TEG uses a mechanical detection system (a pin suspended in a blood sample with a torsion wire that is monitored for motion), while the ROTEM uses an optical detection of the pin motion. ${ }^{88}$ In the Sonoclot Analyzer, blood is added to a cuvette that contains different agents (depending on the test needed). After an automated mixing procedure, a probe that is connected to a transducer is immersed into the sample and starts to oscillate vertically. The changes in impedance to movement imposed by the developing clot are measured. The Sonoclot Analyzer measures ACT, clot rate, and platelet function. $^{88}$

Viscoelastic POC coagulation devices have shown inconsistency in predicting bleeding after cardiopulmonary bypass surgery. ${ }^{89}$ Viscoelastic POC tests have been criticized for being affected by the site of blood draw, delay between collection and analysis, and patient age and sex. ${ }^{90}$

\section{Guidelines for ACT Monitoring during PCI}

To our knowledge, guidelines that address the issue of monitoring the intensity of anticoagulation with various instruments are limited. The joint American College of Cardiology and American Heart Association guideline update on PCI, published in 2005, indicates that UFH is the only anticoagulant for which ACT is used to monitor the intensity of anticoagulation. For PCI, the recommended target ACT is $250-300$ seconds with the HemoTec device and 300-350 seconds with the Hemochron device. When abciximab is used, lower target ACT values ( $\sim 200$ seconds) for both devices are recommended. When eptifibatide or tirofiban is used for angioplasty, target ACT should be approximately 300 seconds. The guidelines indicate that LMWH has little effect on ACT, which should, therefore, not be used for monitoring. This recommendation was not based on studies that specifically examined the effect of LMWH on ACT. ${ }^{65}$

The National Academy of Clinical Biochemistry guidelines also recommend $\mathrm{POC}$ testing to monitor anticoagulation during PCI. ${ }^{33}$ Without IV platelet inhibitors, ACT targets of $>250$ seconds with the Medtronic ACTII or $>300$ seconds with the Hemochron FTCA510 tube assay are recommended. With the IV platelet inhibitors abciximab and eptifibatide, a target of $200-300$ seconds is recommended; with tirofiban, the range is $250-300$ seconds. $^{33}$

\section{Conclusions}

Rapid measurement of the intensity of anticoagulation and, more recently, platelet inhibition allows dose titration of adjuvant medications such as heparin and antiplatelet agents during neuroendovascular procedures and may reduce the rate of thromboembolic and bleeding complications. A standardized reporting system for POC testing and therapeutic targets for the measurement of the intensity of anticoagulation and platelet inhibition in future reports will enable better understanding of the role of these tests in neuroendovascular procedures.

\section{References}

1. Riedel $\mathrm{CH}$, Tietke $\mathrm{M}$, Alfke $\mathrm{K}$, et al. Subacute stent thrombosis in intracranial stenting. Stroke 2009;40:1310-14

2. Ries T, Buhk JH, Kucinski T, et al. Intravenous administration of acetylsalicylic acid during endovascular treatment of cerebral aneurysms reduces the rate of thromboembolic events. Stroke 2006;37:1816-21

3. Qureshi AI, Luft AR, Sharma M, et al. Prevention and treatment of thromboembolic and ischemic complications associated with endovascular procedures. Part II. Clinical aspects and recommendations. Neurosurgery 2000;46: $1360-75$, discussion 75-76

4. Krpski WC, Bass A, Kelly AB, et al. Heparin-resistant thrombus formation by endovascular stents in baboons: interruption by a synthetic antithrombin. Circulation 1990;82:570-77

5. Chaer RA, Graham JA, Mureebe L. Platelet function and pharmacologic inhibition. Vasc Endovascular Surg 2006;40:261-67

6. Hirsh J, Bauer KA, Donati MB, et al. Parenteral anticoagulants: American College of Chest Physicians Evidence-Based Clinical Practice Guidelines (8th Edition). Chest 2008;133(6 suppl):141S-59S

7. Laux V, Perzborn E, Heitmeier S, et al. Direct inhibitors of coagulation proteins: the end of the heparin and low-molecular-weight heparin era for anticoagulant therapy? Thromb Haemost 2009;102:892-99

8. SoRelle R. 1999 Bristol-Myers Squibb cardiovascular metabolic research award: Earl Davie, PhD, defined the system of blood coagulation. Circulation 1999; 100:332

9. Montalescot G, White HD, Gallo R, et al. Enoxaparin versus unfractionated heparin in elective percutaneous coronary intervention. $N$ Engl J Med 2006;355:1006-17

10. El Rouby S, Cohen M, Gonzales A, et al. The use of a HEMOCHRON JR. HEMONOX point of care test in monitoring the anticoagulant effects of enoxaparin during interventional coronary procedures. J Thromb Thrombolysis 2006;21:137-45

11. Saw J, Kereiakes DJ, Mahaffey KW, et al. Evaluation of a novel point-of-care enoxaparin monitor with central laboratory anti-Xa levels. Thromb Res 2003;112:301-06

12. Toschi V, Lettino M, Gallo R, et al. Biochemistry and biology of hirudin. Coron Artery Dis 1996;7:420-28

13. Warkentin TE, Greinacher A, Koster A. Bivalirudin. Thromb Haemost 2008 99:830-39

14. Witting JI, Bourdon P, Maraganore JM, et al. Hirulog-1 and -B2 thrombin specificity. Biochem J 1992;287(pt 2):663-64

15. Bittl JA, Chaitman BR, Feit F, et al. Bivalirudin versus heparin during coronary angioplasty for unstable or postinfarction angina: final report reanalysis of the Bivalirudin Angioplasty Study. Am Heart J 2001;142:952-59

16. Lincoff AM, Kleiman NS, Kottke-Marchant K, et al. Bivalirudin with planned or provisional abciximab versus low-dose heparin and abciximab during percutaneous coronary revascularization: results of the Comparison of Abciximab Complications with Hirulog for Ischemic Events Trial (CACHET). Am Heart J 2002;143:847-53

17. Lincoff AM, Bittl JA, Harrington RA, et al. Bivalirudin and provisional glycoprotein IIb/IIIa blockade compared with heparin and planned glycoprotein IIb/IIIa blockade during percutaneous coronary intervention: REPLACE-2 randomized trial. JAMA 2003;289:853-63

18. Stone GW, McLaurin BT, Cox DA, et al. Bivalirudin for patients with acute coronary syndromes. N Engl J Med 2006;355:2203-16

19. Stone GW, Witzenbichler B, Guagliumi G, et al. Bivalirudin during primary PCI in acute myocardial infarction. N Engl J Med 2008;358:2218-30

20. Swan SK, Hursting MJ. The pharmacokinetics and pharmacodynamics of argatroban: effects of age, gender, and hepatic or renal dysfunction. Pharmacotherapy 2000;20:318-29

21. Chia S, Van Cott EM, Raffel OC, et al. Comparison of activated clotting times obtained using Hemochron and Medtronic analysers in patients receiving anti-thrombin therapy during cardiac catheterisation. Thromb Haemost 2009;101:535-40

22. van Putten J, van de Ruit M, Beunis M, et al. Automated determination of heparin with chromogenic substrates. Haemostasis 1984;14:184-94

23. Tietz NW, ed. Clinical guide to laboratory tests. Philadelphia: W. B. Saunders Company; 1995:228-29

24. Hattersley PG. Activated coagulation time of whole blood. JAMA 1966 196:436-40

25. Van Cott EM. Point-of-care testing in coagulation. Clin Lab Med 2009; 29:543-53

26. Feindt P, Seyfert UT, Volkmer I, et al. Celite and kaolin produce differing activated clotting times during cardiopulmonary bypass under aprotinin therapy. Thorac Cardiovasc Surg 1994;42:218-21

27. Andrew M, MacIntyre B, MacMillan J, et al. Heparin therapy during cardiopulmonary bypass in children requires ongoing quality control. Thromb Haemost 1993;70:937-41

28. Marmur JD, Bullock-Palmer RP, Poludasu S, et al. Avoiding intelligence failures in the cardiac catheterization laboratory: strategies for the safe and ra- 
tional use of dalteparin or enoxaparin during percutaneous coronary intervention. J Invasive Cardiol 2009;21:653-64

29. Lawrence M, Mixon TA, Cross D, et al. Assessment of anticoagulation using activated clotting times in patients receiving intravenous enoxaparin during percutaneous coronary intervention. Catheter Cardiovasc Interv 2004;61:52-55

30. Marmur JD, Anand SX, Bagga RS, et al. The activated clotting time can be used to monitor the low molecular weight heparin dalteparin after intravenous administration. J Am Col Cardiol 2003;41:394-402

31. Dougherty KG, Gaos CM, Bush HS, et al. Activated clotting times and activated partial thromboplastin times in patients undergoing coronary angioplasty who receive bolus doses of heparin. Cathet Cardiovasc Diagn 1992;26:260 -63

32. Zahn R, Haubelt H, Bechtloff S, et al. Laboratory monitoring of heparin and the combination of heparin and the platelet glycoprotein IIb/IIIa receptor antibody fragment abciximab (c7E3) in patients undergoing percutaneous transluminal coronary angioplasty (PTCA). Herz 2003;28:445-52

33. American Association for Clinical Chemistry. Laboratory Medicine Practice Guidelines. 2007: www.aacc.org/members/nacb/LMPG/OnlineGuide/Published Guidelines/poct/Pages/poctpdf.aspx. Accessed December 2010

34. Shimada YJ, Nakra NC, Fox JT, et al. Relation of race (Asian, African-American, European-American, and Hispanic) to activated clotting time after weight-adjusted bolus of heparin during percutaneous coronary intervention. Am J Cardiol 2010;105:629-32

35. Pesola GR, Johnson A, Pesola DA. Percutaneous transluminal coronary angioplasty: comparison of arterial vs. venous activated clotting time. Cathet Cardiovasc Diagn 1996;37:140-44

36. Spinler SA, Wittkowsky AK, Nutescu EA, et al. Anticoagulation monitoring. Part 2. Unfractionated heparin and low-molecular-weight heparin. Ann Pharmacother 2005;39:1275-85

37. Proceedings of the seventh ACCP conference on antithrombotic and thrombolytic therapy: Evidence-based guidelines. Chest 2004;126:172S-696S

38. Ferguson JJ, Dougherty KG, Gaos CM, et al. Relation between procedural activated coagulation time and outcome after percutaneous transluminal coronary angioplasty. J Am Coll Cardiol 1994;23:1061-65

39. Narins CR, Hillegass WB Jr, Nelson CL, et al. Relation between activated clotting time during angioplasty and abrupt closure. Circulation 1996;93:667-71

40. Pinto DS, Lorenz DP, Murphy SA, et al. Association of an activated clotting time $<$ or $=250$ seconds with adverse event rates after percutaneous coronary intervention using tirofiban and heparin (a TAC TICS-TIMI 18 substudy). Am J Cardiol 2003;91:976-78, A4

41. Montalescot G, Cohen M, Salette G, et al. Impact of anticoagulation levels on outcomes in patients undergoing elective percutaneous coronary intervention: insights from the STEEPLE trial. Eur Heart J 2008;29:462-71

42. Chew DP, Bhatt DL, Lincoff AM, et al. Defining the optimal activated clotting time during percutaneous coronary intervention: aggregate results from 6 randomized, controlled trials. Circulation 2001;103:961-66

43. Brener SJ, Bhatt DL, Moliterno DJ, et al. Revisiting optimal anticoagulation with unfractionated heparin during coronary stent implantation. Am J Cardiol 2003;92:1468-71

44. Bertrand OF, Rodes-Cabau J, Rinfret S, et al. Impact of final activated clotting time after transradial coronary stenting with maximal antiplatelet therapy. Am J Cardiol 2009;104:1235-40

45. Schumacher HC, Meyers PM, Higashida RT, et al. Reporting standards for angioplasty and stent-assisted angioplasty for intracranial atherosclerosis. Stroke 2009;40:e348-65

46. Jiang WJ, Wang YJ, Du B, et al. Stenting of symptomatic M1 stenosis of middle cerebral artery: an initial experience of $\mathbf{4 0}$ patients. Stroke 2004;35:1375-80

47. Henkes H, Miloslavski E, Lowens S, et al. Treatment of intracranial atherosclerotic stenoses with balloon dilatation and self-expanding stent deployment (WingSpan). Neuroradiology 2005;47:222-28

48. Lylyk P, Cohen JE, Ceratto R, et al. Angioplasty and stent placement in intracranial atherosclerotic stenoses and dissections. AJNR Am J Neuroradiol 2002;23:430-36

49. Levy EI, Boulos AS, Guterman LR. Stent-assisted endoluminal revascularization for the treatment of intracranial atherosclerotic disease. Neurol Res 2002;24:337-46

50. Castellan L, Causin F, Danieli D, et al. Carotid stenting with filter protection: correlation of ACT values with angiographic and histopathologic findings. J Neuroradiol 2003;30:103-08

51. Yokote H, Terada T, Ryujin K, et al. Percutaneous transluminal angioplasty for intracranial arteriosclerotic lesions. Neuroradiology 1998;40:590-96

52. Qureshi AI, Suri MF, Siddiqui AM, et al. Clinical and angiographic results of dilatation procedures for symptomatic intracranial atherosclerotic disease. J Neuroimaging 2005; 15:240-49

53. Gress DR, Smith WS, Dowd CF, et al. Angioplasty for intracranial symptomatic vertebrobasilar ischemia. Neurosurgery 2002;51:23-27, discussion 27-29

54. Saw J, Bajzer C, Casserly IP, et al. Evaluating the optimal activated clotting time during carotid artery stenting. Am J Cardiol 2006;97:1657-60

55. Yadav JS, Wholey MH, Kuntz RE, et al. Protected carotid-artery stenting versus endarterectomy in high-risk patients. N Engl J Med 2004;351:1493-501

56. Brott TG, Hobson RW 2nd, Howard G, et al. Stenting versus endarterectomy for treatment of carotid-artery stenosis. N Engl J Med 2010;363:11-23. Epub 2010 May 26

57. Cavusoglu E, Lakhani M, Marmur JD. The activated clotting time (ACT) can be used to monitor enoxaparin and dalteparin after intravenous administration. J Invasive Cardiol 2005;17:416-21

58. Marmur JD, Lakhani M, El Rouby S, et al. A novel point-of-care assay for the monitoring of low-molecular weight heparins in the cardiac catheterization laboratory. I Invasive Cardiol 2008;20:449-54

59. Silvain J, Beygui F, Ankri A, et al. Enoxaparin anticoagulation monitoring in the catheterization laboratory using a new bedside test. J Am Coll Cardiol 2010;55:617-25

60. Casserly IP, Topol EJ, Jia G, et al. Effect of abciximab versus tirofiban on activated clotting time during percutaneous intervention and its relation to clinical outcomes: observations from the TARGET trial. Am J Cardiol 2003 . 92:125-29

61. Moliterno DJ, Califf RM, Aguirre FV, et al. Effect of platelet glycoprotein IIb/ IIIa integrin blockade on activated clotting time during percutaneous transluminal coronary angioplasty or directional atherectomy (the EPIC trial): evaluation of c7E3 Fab in the Prevention of Ischemic Complications trial. Am J Cardiol 1995;75:559-62

62. Ammar T, Scudder LE, Coller BS. In vitro effects of the platelet glycoprotein IIb/IIIa receptor antagonist c7E3 Fab on the activated clotting time. Circulation 1997;95:614-17

63. Dauerman HL, Ball SA, Goldberg RJ, et al. Activated clotting times in the setting of eptifibatide use during percutaneous coronary intervention. J Thromb Thrombolysis. 2002;13:127-32

64. Furman MI, Krueger LA, Frelinger AL 3rd, et al. GPIIb-IIIa antagonist-induced reduction in platelet surface factor $\mathrm{V} / \mathrm{Va}$ binding and phosphatidylserine $\mathrm{ex}$ pression in whole blood. Thromb Haemost 2000;84:492-98

65. Smith SC Jr, Feldman TE, Hirshfeld JW Jr, et al. ACC/AHA/SCAI 2005 guideline update for percutaneous coronary intervention: a report of the American College of Cardiology/American Heart Association Task Force on Practice Guidelines (ACC/AHA/SCAI Writing Committee to Update 2001 Guidelines for Percutaneous Coronary Intervention). Circulation 2006;113:e166-286

66. Tolleson TR, O'Shea JC, Bittl JA, et al. Relationship between heparin anticoagulation and clinical outcomes in coronary stent intervention: observations from the ESPRIT trial. J Am Coll Cardiol 2003;41:386-93

67. Hemochron [package insert]. http://www.itcmed.com/Products 2010

68. Pan C-M, Jobes D, Van Riper D, et al. A modified microsample ACT test for heparin monitoring. J Extra Corpor Technol 1996;28:16-20

69. Despotis GJ, Joist JH, Hogue CW Jr, et al. The impact of heparin concentration and activated clotting time monitoring on blood conservation: a prospective, randomized evaluation in patients undergoing cardiac operation. J Thorac Cardiovasc Surg 1995; 110:46-54

70. Jaryno SA, Zucker ML, LaDuca FM. The Hemochron Response RxDx heparin and protamine dosing system. J Extra Corpor Technol 2004;36:258-62

71. Shore-Lesserson L, Reich DL, DePerio M. Heparin and protamine titration do not improve haemostasis in cardiac surgical patients. Can J Anaesth $1998 ; 45: 10-18$

72. Silvain J, Beygui F, Ankri A, et al. Enoxaparin anticoagulation monitoring in the catheterization laboratory using a new bedside test. J Am Coll Cardiol 2010;55:617-25

73. Medtronic; Minneapolis, Minnesota. http://www.medtronic.com/for-health care-professionals/products-therapies/cardiovascular/therapies/perfusion/ index.htm\#tab2. Accessed December 2010

74. Despotis GJ, Alsoufiev AL, Spitznagel E, et al. Response of kaolin act to haparin: Evaluation with an automated assay and higher heparin doses. Annal Thoracic Surg 1996;61:795-99

75. Despotis GJ, Summerfield AL, Joist JH, et al. Comparison of activated coagulation time and whole blood heparin measurements with laboratory plasma anti-xa heparin concentration in patients having cardiac operations. $J$ Thoracic Cardiovasc Surg 1994;108:1076-82

76. Garvin S, Fitzgerald DC, Despotis G, et al. Heparin concentration-based anticoagulation for cardiac surgery fails to reliably predict heparin bolus dose requirements. Anesth Analg 2010;111:849-55. Epub 2009 Oct 27

77. Gravlee G, Davis R, Stammers A, et al. Cardiopulmonary Bypass: Principles and Practice. 3rd ed. Philadelphia: Lippincott Williams \& Wilkins; 2008

78. Owings JT, Pollock ME, Gosselin RC, et al. Anticoagulation of children undergoing cardiopulmonary bypass is overestimated by current monitoring techniques. Arch Surg 2000;135:1042-47

79. Helft G, Bartolomeo P, Zaman AG, et al. The heparin management test: a new device for monitoring anticoagulation during coronary intervention. Thrombosis Res 1999;96:481-85

80. Tsimikas S, Beyer R, Hassankhani A. Relationship between the heparin management test and the HemoTec activated clotting time in patients undergoing percutaneous coronary intervention. J Thromb Thrombolysis 2001;11:217-21

81. Ganter MT, Dalbert S, Graves K, et al. Monitoring activated clotting time for combined heparin and aprotinin application: an in vitro evaluation of a new aprotinin-insensitive test using SONOCLOT. Anesth Analg 2005;101:308-14

82. Ganter MT, Monn A, Tavakoli R, et al. Monitoring activated clotting time for 
combined heparin and aprotinin application: in vivo evaluation of a new aprotinin-insensitive test using Sonoclot. Eur J Cardiothorac Surg 2006; 30:278-84

83. Paniccia R, Fedi S, Carbonetto F, et al. Evaluation of a new point-of-care celiteactivated clotting time analyzer in different clinical settings: the i-STAT celite-activated clotting time test. Anesthesiology 2003;99:54-59

84. Bosch YP, Ganushchak YM, de Jong DS. Comparison of ACT point-of-care measurements: repeatability and agreement. Perfusion 2006;21:27-31

85. Espana F, Ratnoff OD. Activation of Hageman factor (factor XII) by sulfatides and other agents in the absence of plasma proteases. J Lab Clin Med 1983;102:31-45

86. Leyvi G, Shore-Lesserson L, Harrington D, et al. An investigation of a new activated clotting time "MAX-ACT" in patients undergoing extracorporeal circulation. Anesth Analg 2001;92:578-83

87. Prisco D, Paniccia R. Point-of-care testing of hemostasis in cardiac surgery. Thromb J 2003;1:1

88. Ganter MT, Hofer CK. Coagulation monitoring: current techniques and clinical use of viscoelastic point-of-care coagulation devices. Anesth Analg 2008;106:1366-75

89. Wang JS, Lin CY, Hung WT, et al. Thromboelastogram fails to predict postoperative hemorrhage in cardiac patients. Ann Thorac Surg 1992;53:435-39

90. Luddington RJ. Thrombelastography/thromboelastometry. Clin Lab Haematol 2005;27:81-90 